\title{
Characterization and physical studies of Poly (vinyl alcohol)/ Sodium alginate/ multiwall carbon nanotube biocomposites
}

\author{
M.S. Meikhail' ${ }^{1}$, A.M. Hezma ${ }^{2}$, B.A. Mohamed ${ }^{1}$ \\ ${ }^{1}$ Physics Department, Faculty of Science, Mansoura University, Mansoura, 35516, \\ ${ }^{2}$ Spectroscopy Dept., Physics Division, National Research Center, 33 Elbehouth St., \\ Cairo, 12311, Egypt.
}

\begin{abstract}
$\mathbf{M}$ ULTIWALL carbon nanotubes (MWCNTs) were added to poly-(vinyl alcohol) (PVA)/ sodium alginate (SA) bio-blend. PVA/SA was prepared with ratio (80/20) wt \%. Different ratios of MWCNTs were added to PVA/SA blend to study the change in its physicochemical properties. The prepared films were characterized by Fourier transform infrared spectroscopy (FTIR), Scanning electron microscopy (SEM), Differentierties that are preferably al scanning calorimetry (DSC) and X-ray diffraction (XRD) analysis to confirm the good miscibility of the two biopolymers and the uniform distribution of the MWCNTs. Mechanical properties, thermal stability, morphological properties, and crystallinity of the polymer matrix before and after blending were evaluated. The enhancement of structural and mechanical properties was observed during the addition of MWCNTs. PVA/SA with the optimum concentration of MWCNTs hoped to be suitable for the field of drug delivery and other various medical applications.
\end{abstract}

Keywords: MWCNTs, SA, FTIR, XRD, DSC, DMA

\section{Introduction}

In the past few years, the use of individual polymers as a matrix was limited by the problems associated their limited physical and mechanical properties. So, blends have become technologically important because blending two or more polymers may be useful to modify some physical and structural properties of polymers [1-4], It includes physical combination of biopolymers leads to formation a new material with some properties that are preferable of any one of the component polymers $[5,6]$, which can be used in different applications that cannot be achieved by one polymer alone.

Poly (vinyl alcohol) (PVA), is a semicrystalline polymer biocompatible, highly hydrophilic and thermoplastic polymer [7]. PVA is water-soluble, and its water solubility depends on its molecular weight and degree of hydrolysis $[8,9]$. PVA is also nontoxic, good charge storage capacity, dopant-dependent optical and electrical properties and the potential material having high dielectric strength [10].
Sodium alginate (SA), a natural biodegradable polymer with large relativemolecular mass, containing a long chain structures of polymannuronic acids and polyaluronic acid [11], extracted from brown seaweed that grows in cold water regions [12], and SA have unique properties such as non-toxicity, tasteless, biocompatibility, low cost and its biological origin $[13,14]$.

A lot of applications have been reported for the copolymers including burn dressings, hydrogel membranes, tissue engineering and controlled drug delivery. Natural polymers such as sodium alginate have excellent biodegradability and biocompatibility but poor mechanical properties. This drawback can be overcome by using a synthetic polymer in combination with the natural polymer to obtain a modified polymer having desirable properties [15]. PVA interacts with SA through hydrogen bonds to form PVA/ SA composite films that are smooth, flexible, transparent and uniform [16].

Multiwall Carbon nanotubes (MWCNTs) have received much attention in recent years not only due 
to its excellent physical and mechanical proprieties but also its wide range of potential applications [17, 18, and 19]. One of the most interesting applications of MWCNTs is the polymer/CNTs nanocomposites. The higher mechanical, thermal properties and verity of bonding functional groups of MWCNTs make them ideal candidates as reinforcing fillers in polymer nanocomposites designed for structure or functional applications $[17,18]$. Recently, much research on a fabrication of biopolymers such as chitosan, [19] polycarbonate, [20] poly (methyl methacrylate), [21] and poly (vinyl alcohol) [22] with MWCNTs nanocomposites has been investigated. Two factors for MWCNTs as reinforcing fillers for polymers: homogenous dispersion in the polymer matrix and efficient adhesion between the sidewall of MWCNTs and the polymer matrix [23-25].

In this work, we have added (MWCNTs) to PVA/SA bio-blend and characterized the prepared films by using various techniques to know the effect of MWCNTs on this blend to use in the medical application like drug delivery.

\section{Experimental details}

\section{Materials}

Poly (vinyl alcohol) (PVA) was obtained from Qualikems Fine Chemicals Pvt.Ltd $\mathrm{M}_{\mathrm{w}}=14,000$. Sodium alginate (SA) powder was purchased from Sigma-Aldrich, United Kingdom. A Multiwalled carbon nanotube (MWCNTs) was supplied by Bayer Material Science AG, Germany.

\section{Sample Preparation}

Pure PVA and SA were dissolved in distilled water and mixed with PVA/SA ratio $(80 / 20) \mathrm{Wt} \%$ with continuous stirring for $2 \mathrm{~h}$ to ensure the complete mixing of the two polymers. MWCNTs were added to the polymer solution with various concentrations which listed in the table (1). To ensure the good dispersion of MWCNTs in the polymer matrix a probe sonicator device was used with operating frequency $100 \mathrm{HZ}$ for $1 \mathrm{~h}$. Then the solution was poured into Petri dishes and was dried in oven at $60{ }^{\circ} \mathrm{C}$ to prepare pure and filled polymeric films. After drying, the films were cut into suitable pieces for different measurements.

\section{Physical measurements}

FT-IR spectra of the prepared samples were examined by using (Nicolet iS10, USA) single beam spectrometer; which obtained in the spectral range of $4000-400 \mathrm{~cm}^{-1}$. X-ray diffraction (XRD) patterns were obtained using PAN analytical $X^{\prime}$ Pert PRO system which using $\mathrm{CuK}_{\alpha}$ radiation (tube operating at $30 \mathrm{kV}$, Bragg's angle $(2 \theta)$ in the range of $5-80^{\circ} \mathrm{c}$ and wavelength $\lambda=1.54 \AA$ ). UV-Vis absorption spectra were measured in the spectral wavelength range 200-1100 nm using spectrophotometer (T80+, UV/Vis. spectrometer, PG Instrument Ltd.) to study the changes in structures of the samples. DSC of the studied samples using (SETARAM LabsysTM TG-DSC 16 , France), with measuring the temperature range from room temperature $30^{\circ} \mathrm{C}$ to $700^{\circ} \mathrm{C}$ and heating rate by $10^{\circ} \mathrm{C} / \mathrm{min}$. Scanning electron microscope (SEM) which studied surface nature of the samples by using JEOL JSM-840A, operating at $30 \mathrm{kV}$ accelerating voltage. Dynamic mechanical analysis (DMA) to study the improvement of MWCNTs on the blend which using Universal Testing Machine (Shimadzu UTM, Japan), at room temperature. The membrane specimens were $30 \mathrm{x}$ $10 \mathrm{~nm}$. Measurements carried out at the constant speed of crossheads movement (1mm / minute). Three measurements were performed at least for each sample and the mean values were reported.

\section{Results and Discussion}

\section{FT-IR Studies}

FT-IR spectra of the blend and its composites have been measured in the spectral range 4000 $-400 \mathrm{~cm}^{-1}$. FTIR spectrum of pure MWCNTs represented in Figure (1). MWCNTs have three distinctive peaks $\mathrm{C}=\mathrm{O}, \mathrm{O}-\mathrm{H}, \mathrm{C}-\mathrm{O}$ which are considered as a result of oxidation forming the $\mathrm{COOH}$ groups on the surface of MWCNTs. The absorption band at $1744 \mathrm{~cm}^{-1}$ refers to $\mathrm{C}=\mathrm{O}$ stretching, while the absorption band at $1416 \mathrm{~cm}^{-1}$ and $1032 \mathrm{~cm}^{-1}$ are associated with $\mathrm{O}-\mathrm{H}$ bending and $\mathrm{C}-\mathrm{O}$ stretching respectively. FT-IR absorption bands positions and the assignments are listed in Table (2) [26-29].

TABLE 1. sample preparation.

\begin{tabular}{c|c|c|c|c|c|c}
\hline sample & S0 & S1 & S2 & S3 & S4 & S5 \\
\hline $\begin{array}{c}\text { MWCNTs (wt } \% \\
\text { added) }\end{array}$ & 0 & 0.008 & 0.02 & 0.05 & 0.08 & 0.1 \\
\hline
\end{tabular}

J. Text.Color. Polym. Sci., 15, No. 1 (2018) 


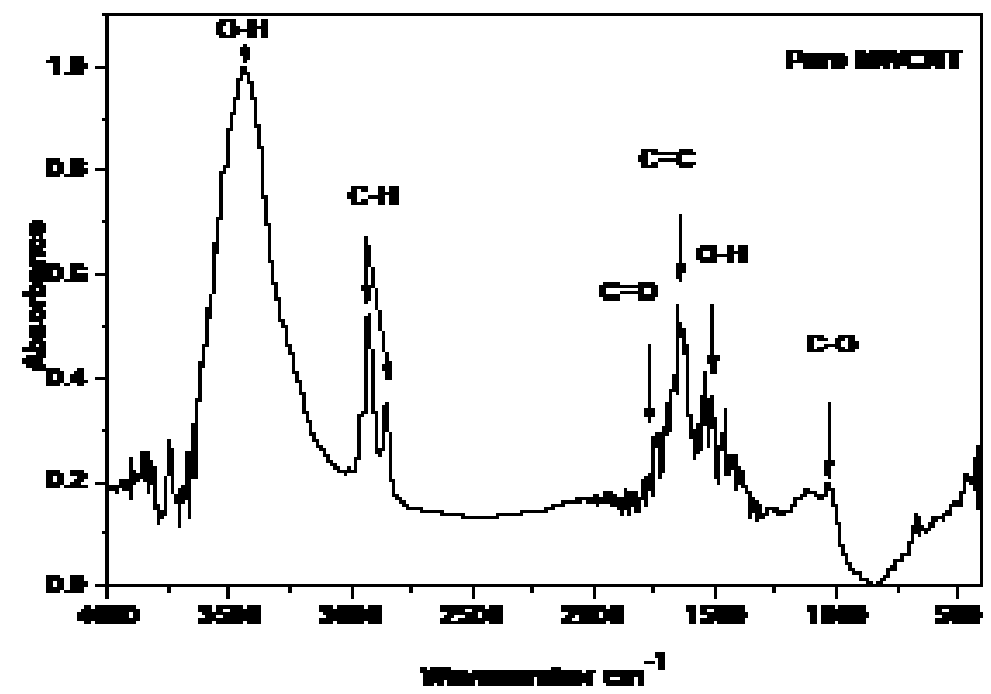

Fig 1. FTIR absorption spectra of pure MWCNTs.

TABLE 2. FTIR band assignment of pure MWCNTs.

Wavenumbers

$\left(\mathrm{cm}^{-1}\right)$
Band assignment

O-H stretch of hydroxyl group

$\mathrm{CH}$ stretching

$\mathrm{C}=\mathrm{O}$ stretching

$\mathrm{C}=\mathrm{C}$ stretching

$\mathrm{OH}$ bending

$\mathrm{C}-\mathrm{O}$ stretching
FTIR spectrum of pure PVA/SA blend with different concentrations of MWCNTs represented in Figure (2), which display characteristic peaks of $\mathrm{O}-\mathrm{H}$ stretching vibration at $3357 \mathrm{~cm}^{-1}, \mathrm{C}=\mathrm{O}$ stretching vibration at $1734 \mathrm{~cm}^{-1}$, symmetric $\mathrm{COO}$ - stretching vibration at $1608 \mathrm{~cm}^{-1}, \mathrm{CH}_{2}$ bending modes at $1260 \mathrm{~cm}^{-1}$ and $\mathrm{CH}$ asymmetric stretching at $2942 \mathrm{~cm}^{-1}$ for pure blend and FT-IR absorption bands positions and the assignments are listed in Table (3) [27-29]. When adding MWCNTs with different concentrations to the pure blend, the peaks at 3357, $1095 \mathrm{~cm}^{-1}$ beginning to be more boarding and the intensity of some peaks was changed such as the peaks at 2942, 1734, 1420, 946 and $826 \mathrm{~cm}^{-1}$, and observed that the peak at $1608 \mathrm{~cm}^{-1}$ has shifted, this result confirms the good miscibility between MWCNTs and the blend films.

\section{$X$-ray Diffraction}

X-ray patterns of pure MWCNTs, PVA/SA biopolymer blend films and its biocomposites with MWCNTs were represented in Figures (3) and (4) respectively. It is clear that in the pure blend a sharp peak centered at $2 \theta=20^{\circ}$ attributed to the diffraction lattice plane (110) of the semicrystalline PVA [30]. From the graphs; we can be observed that the XRD patterns of the PVA/SA/ MWCNTs biocomposites kept the characteristic peaks of pure PVA, that means the incorporation of MWCNTs did not significantly affect the crystal structure of PVA, also when the concentrations increase the intensity of the peak began to decrease and shift, this may be corresponding to the incorporation of MWCNTs with the blend in high concentrations. 
TABLE 3. FTIR band assignment of pure PVA/SA blend.

\begin{tabular}{cc}
$\begin{array}{c}\text { Wavenumbers } \\
\left(\mathbf{c m}^{-1}\right)\end{array}$ & Band assignment \\
3357 & $\mathrm{O}-\mathrm{H}$ stretching vibration \\
2942 & $\mathrm{CH}_{2}$ stretching vibration \\
1734 & $\mathrm{C}=\mathrm{O}$ stretching vibration \\
1608 & COO- asymmetric stretching $\quad$ COO- symmetric \\
1420 & stretching \\
1260 & $\mathrm{CH}$ bending \\
946 & $\mathrm{C}-\mathrm{O}$ stretching \\
826 & $\mathrm{C}-\mathrm{C}$ stretching \\
& $\mathrm{CH}$ rocking \\
\hline
\end{tabular}

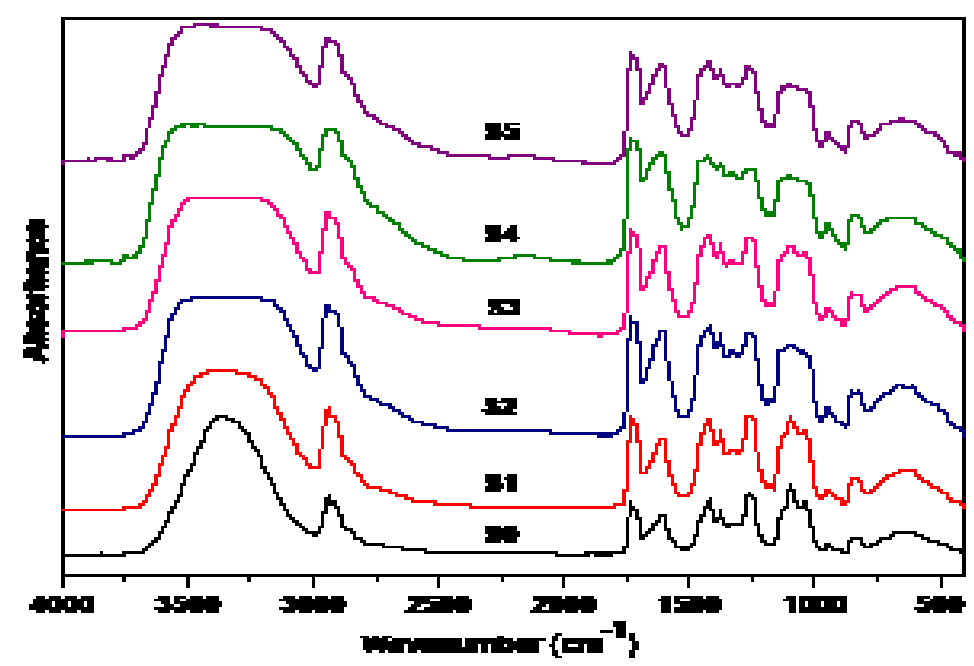

Fig 2. Infrared spectra of PVA/SA pure blend filled with different concentrations of MWCNTs.

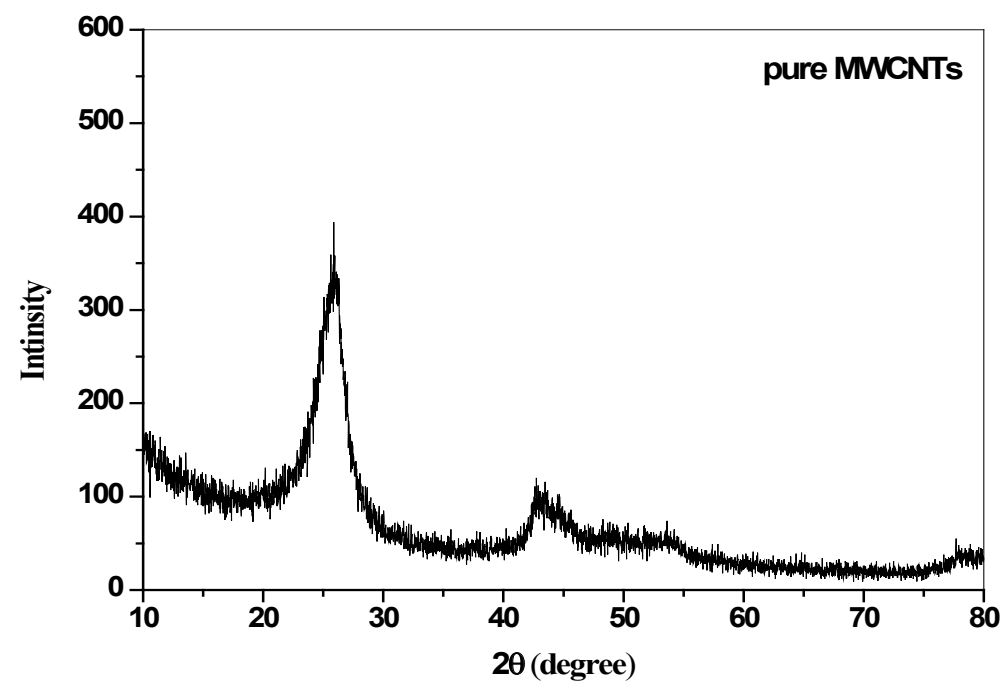

Fig 3. The X-ray diffraction for pure MWCNTs. 


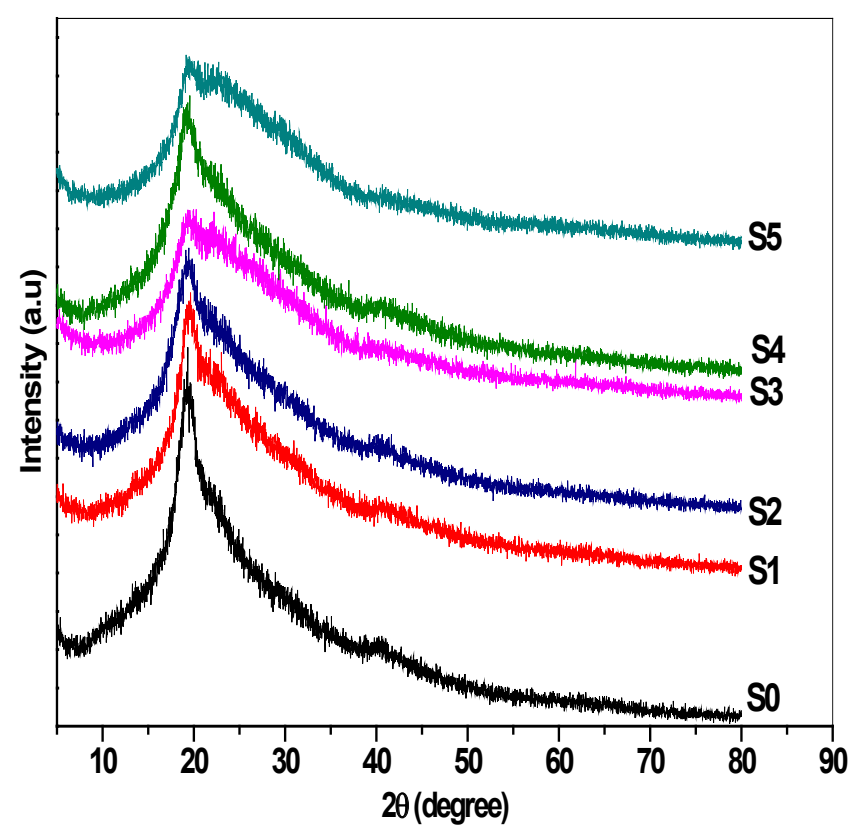

Fig 4.The X-ray diffraction for PVA/SA pure blend filled with different concentrations of MWCNTs

\section{UV-Visible studies}

$\mathrm{UV}-\mathrm{Vis}$ spectroscopic analysis of PVA/SA blend films filled with different concentration of MWCNTs represented in the Figure (5-a), which shows that the sharp edge in the range $200-230$ $\mathrm{nm}$ that shows in Figure (5-b), was shifted to the longer wavelength with increasing MWCNTs concentration that refers to the incorporation between the PVA/SA blend and MWCNTs and also shows that no absorption peaks at longer wavelength $>230 \mathrm{~nm}$.

Determination of optical energy gap (Eg):-

Using UV-visible absorption spectra, it used to examine direct and indirect transition. Using the Per-Lambert-Bauger experimental relationship to calculate the absorption coefficient $(\alpha)$

$$
\alpha=2.303(\mathrm{~A} / \mathrm{d})
$$

where $\mathrm{A}$ is the absorbance, $\mathrm{d}$ is the thickness of the sample.

The optical band gap was detected from the spectral absorption analysis of absorption close to the absorption edge. The relation between the absorption coefficient $(\alpha)$ and the incident photon energy (hv) can be determined by using Tauc's relationship [31].

$$
\alpha(v) h v=B(h v-E g)^{r}
$$

where: B is a constant, Eg is the optical energy gap, $\mathrm{h}$ is plank's constant, $\alpha$ is the absorption coefficient, $\boldsymbol{v}$ represent the photon frequency and $r$ is called the power factor of the transition mode.

The values of (r) for direct allowed, indirect allowed, direct forbidden and indirect forbidden transitions are $n=1 / 2,2,3 / 2$ and 3 , respectively. Davis et al, observed the essential band gap for direct and the indirect transition by plotting both $(\alpha h v)^{1 / 2}$ and $(\alpha h v)^{2}$ versus photon energy (hv) in Figure 6 (a) and (b) respectively, following the equations [32]:

$$
\begin{aligned}
& (\mathrm{n} \alpha \mathrm{h} v)^{2}=\mathrm{C}_{1}\left(\mathrm{~h} v-\mathrm{E}_{\mathrm{gd}}\right) \\
& (\mathrm{n} \alpha \mathrm{h} v)^{1 / 2}=\mathrm{C}_{2}\left(\mathrm{~h} v-\mathrm{E}_{\mathrm{gi}}\right)
\end{aligned}
$$

where: $\mathrm{E}_{\mathrm{gd}}$ is the direct band gap, $\mathrm{h}$ is Planck's constant, $\mathrm{C}_{1}, \mathrm{C}_{2}$ are constants, $\mathrm{h} v$ is the photon energy, $\alpha$ is the absorption coefficient, $\mathrm{n}$ is an integer and $\mathrm{E}_{\mathrm{gi}}$ is the indirect band gap.

The direct band gap and the indirect band gap are listed in Table (4). This shows the direct and indirect band gap values decreased with increased the concentration of MWCNTs, but after $(0.08 \mathrm{wt} \%)$ concentration shows disturbances in direct and indirect band gap values where the values of direct and indirect begin to increase that due to the bad dispersion of MWCNTs. 


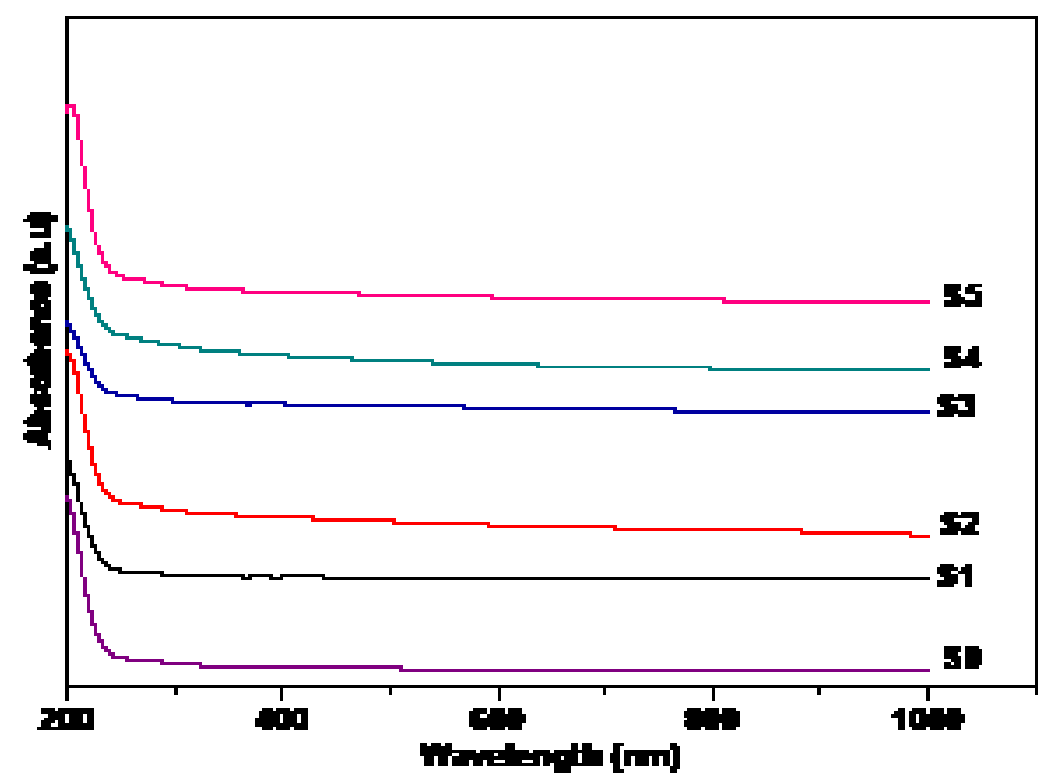

Fig. 5-a. UV-Vis. Spectra of pure PVA/SA blend filled with different concentrations of MWCNT

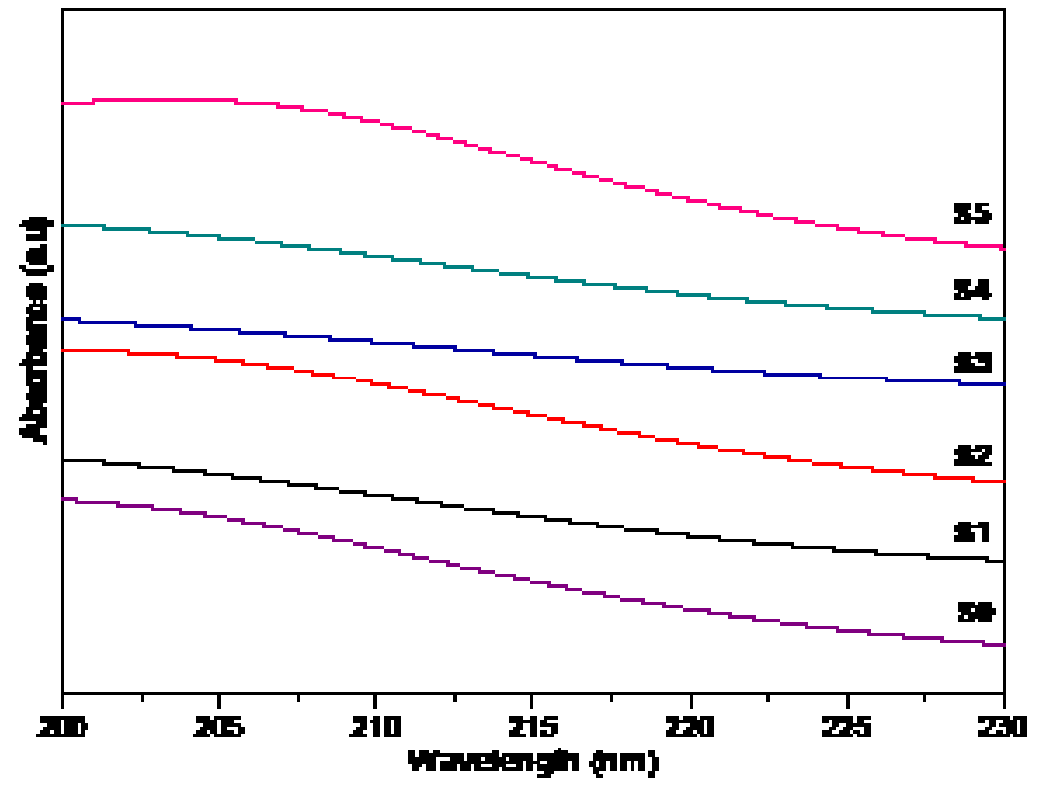

Fig 5-b. The sharp edge for pure PVA/SA blend filled with different concentrations of MWCNTs in the range $200-230 \mathrm{~nm}$.

TABLE 4.The energy gap between the direct and indirect transition.

\begin{tabular}{cccc}
\hline Sample & MWCNTs Conc wt\% & direct band gap (eV) & Indirect band gap (eV) \\
\hline S0 & 0 & 4.9 & 5.6 \\
S1 & 0.008 & 4.8 & 5.55 \\
S2 & 0.02 & 4.68 & 5.5 \\
S3 & 0.05 & 4.5 & 5.43 \\
S4 & 0.08 & 4.4 & 5.4 \\
S5 & 0.1 & 4.8 & 5.5 \\
\hline
\end{tabular}

J. Text.Color. Polym. Sci., 15, No. 1 (2018) 

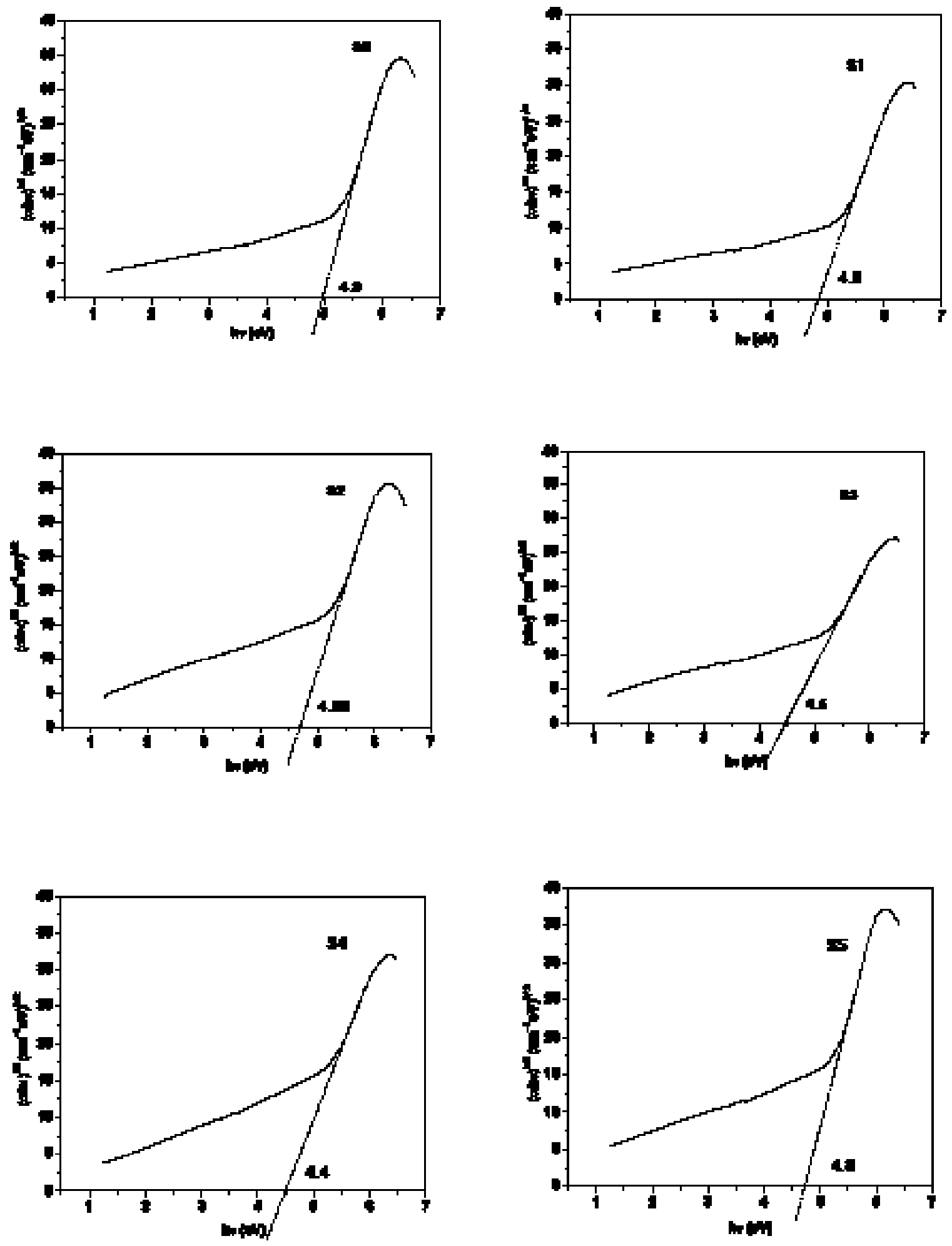

Fig. 6-a. The relation between ( $\alpha \mathrm{hv}) \mathrm{1} / 2$ and (hv). 

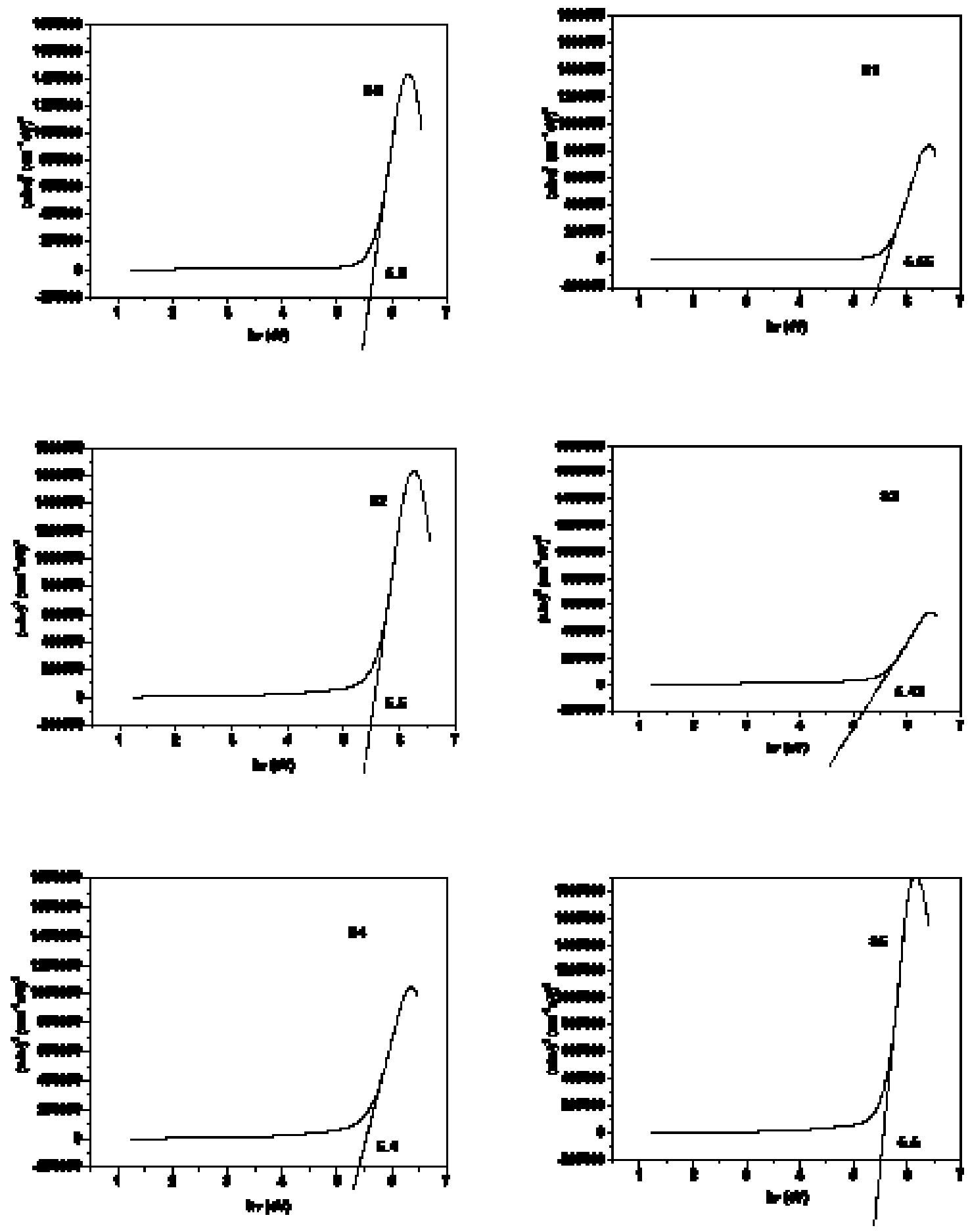

Fig. 6-b. The relation between ( $\alpha \mathrm{hv}) 2$ and (hv). 


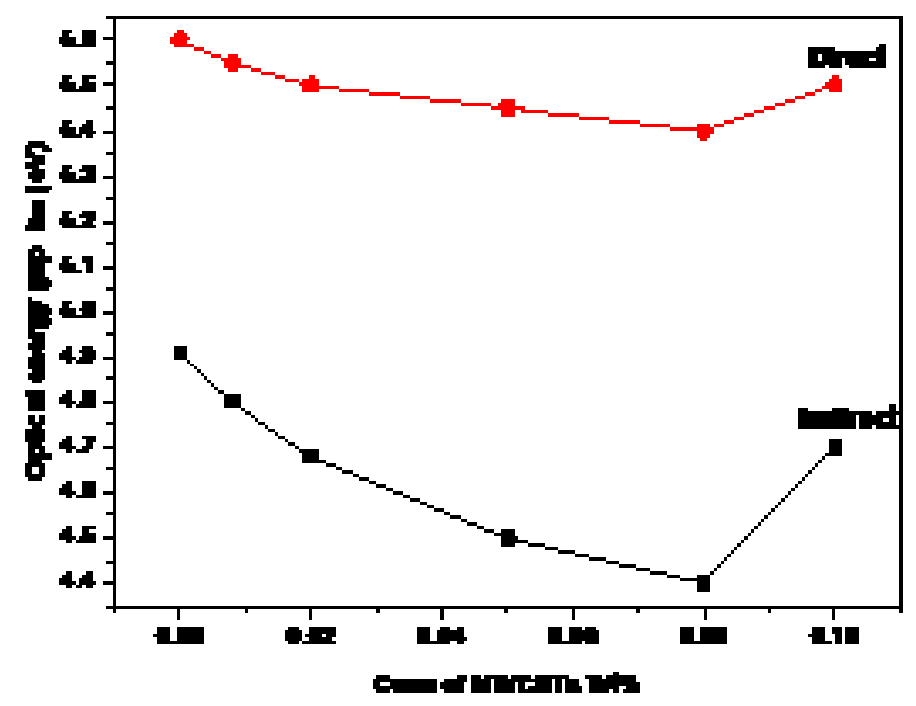

Fig. 7. Comparison between direct and indirect calculated energy gap values

\section{Morphology studies}

A scanning electron microscope (SEM) used to investigate the surface Morphology. Figure 8 (a, b, c, d, e and f) shows the SEM of PVA/SA filled with various concentration of MWCNTs $(0$, $0.008,0.02,0.05,0.08$ and $0.1 \mathrm{wt} \%$ ) respectively. In Figure 8 the PVA/SA biopolymer blend shows the smooth appearance of the blend surface, and then by adding MWCNTs filler with different concentrations to the biopolymer blend, the surface of biocomposites become rougher and the grain size was formed. The formation of granules in polymer composite after addition the MWCNTs may be due to the attraction force between the MWCNTs surface and the polymer matrix due to the hydrophilic interphase around the tubes. The boundaries of granules formed at the tubes ends and appear at the biocomposite surface.

After that shows pools of MWCNTs on the blend in the higher concentration $(0.1 \mathrm{Wt} \%)$ that may be due to the bad dispersion of MWCNTs. That's mean the morphology of PVA/SA/MWCNTs biocomposites is affected by the addition of MWCNTs. These results agree with the XRD and energy gab values which confirm the significant change in the structural properties of the biocomposite at higher concentration of MWCNTs.

\section{Differential scanning calorimetry}

Differential scanning calorimetry is a key thermal analysis technique that used to determine the physical and chemical changes such as glass transition temperatures ( $\mathrm{Tg}$ ), phase transitions, and melting parameters (melting point Tm, thermal decomposition temperature
Td). Differential scanning calorimetry (DSC) of pure PVA/SA blend and PVA/SA that doped with different concentrations of MWCNTs were presented in Figure (9).

The DSC curves show exothermic and endothermic peaks. For pure PVA/SA curve a small endothermic transition observed at about $91^{\circ} \mathrm{C}$ attributed to ( $\mathrm{Tg}$ ) that may be ascribed to bound water in the sample prepared [33] and also due to the formation of strong intermolecular hydrogen bonding because sodium alginate has hydroxyl and carboxylate groups [34]. The thermogram shows two endothermic peaks (Tm), and (Td). Endothermic peak (Tm) observed at about $190.2^{\circ} \mathrm{C}$ which attributed to the melting point of PVA [35] and the other endothermic peak (Td) observed at $312.5^{\circ} \mathrm{C}$. In Table (5) the values of the transition temperatures ( $\mathrm{Tg}, \mathrm{Tm}$, and $\mathrm{Td}$ ) for PVA/SA/MWCNTs biocomposite are reported.

In this table, the position of melting point (Tm) doesn't show any significant change it its values compared with the pure polymer blend. However, the values of Tm and Td show increase in their values than the pure blend except in the Tm value of sample S3. This could be due to the increase of amorphous phase in this sample. These results agree with XRD results and are confirmed by the mechanical behavior tests of the samples.

\section{Mechanical testing}

The stress-strain test was studied to know the effect of MWCNTs on the mechanical properties PVA/SA blend. The stress-strain curve of the prepared samples with MWCNTs biocomposite ratios of $0.008,0.02,0.05,0.08$ and $0.1 \mathrm{wt} \%$ was J. Text.Color. Polym. Sci. ,15, No. 1 (2018) 


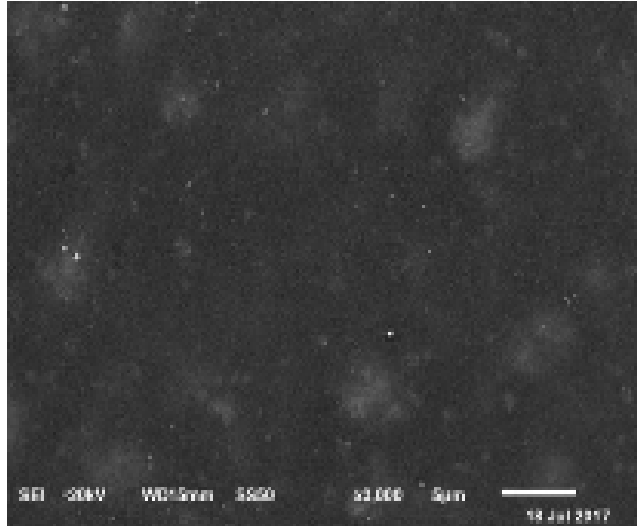

(a)

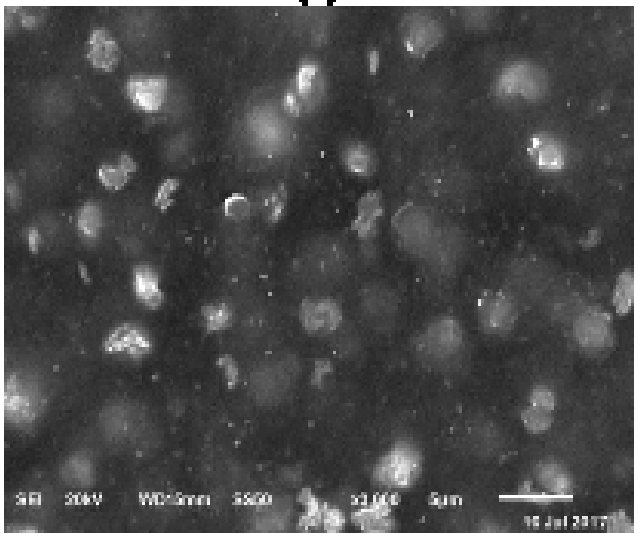

(c)

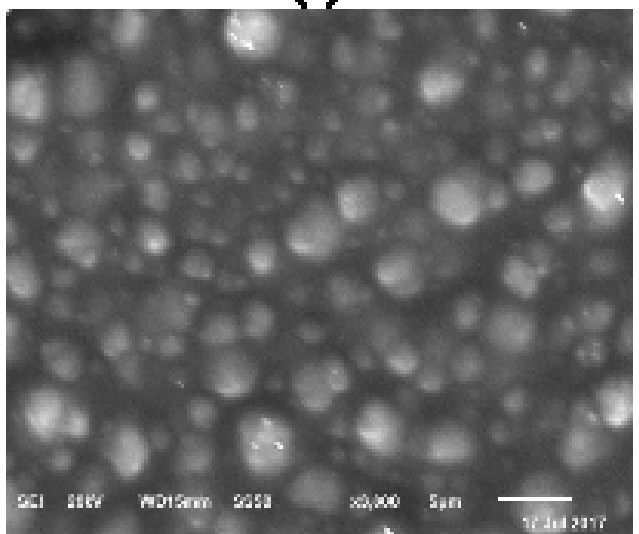

(c)

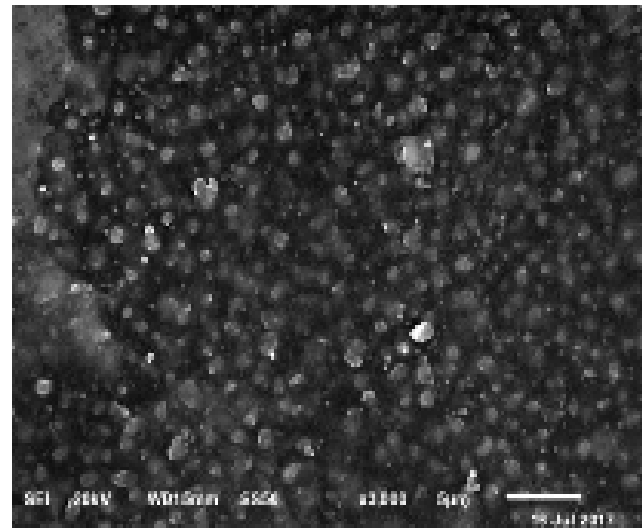

(b)

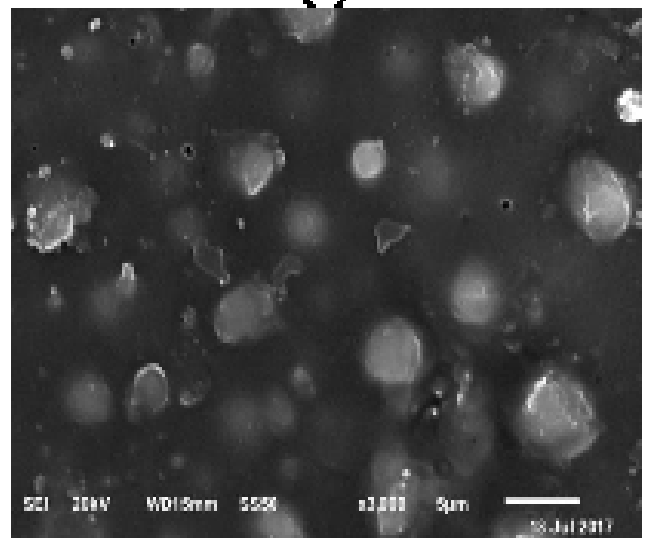

(d)

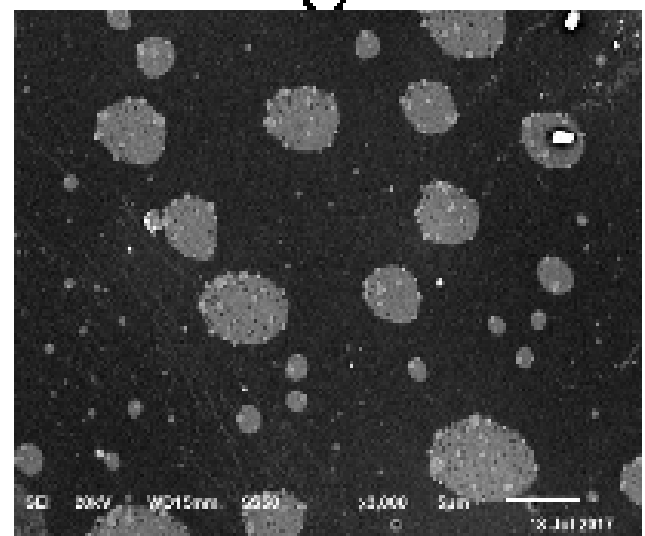

(t)

Fig. 8. SEM images for PVA/SA pure blend (a): S0 and blend filled with different concentrations of MWCNTs (b): S1, (c): S2, (d): S3, (e): S4, (f): S5. 


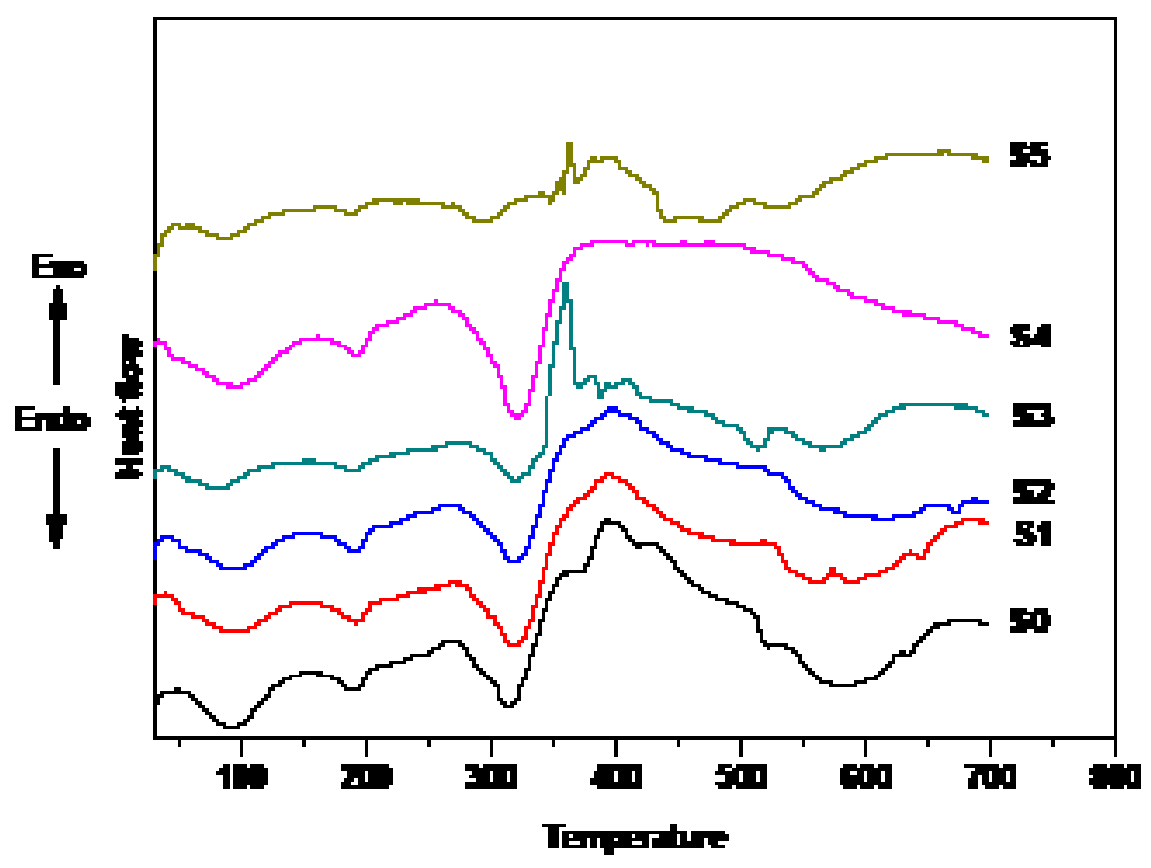

Fig. 9. DSC curves of PVA/SA/MWCNTs biocomposite films.

TABLE 5. The values of Tg, Tm, and Td for PVA/SA/MWCNTs biocomposites.

\begin{tabular}{ccccc}
\hline Sample & $\begin{array}{l}\text { MWCNTs } \\
\text { Conc wt\% }\end{array}$ & Tg & Tm & Td \\
\hline S0 & 0 & 91 & 190.2 & 312.5 \\
S1 & 0.008 & 96.2 & 191.6 & 318 \\
S2 & 0.02 & 96.2 & 191.6 & 321 \\
S3 & 0.05 & 83 & 192 & 320.4 \\
S4 & 0.08 & 96 & 191 & 295.6 \\
\hline
\end{tabular}

represented in Figure (10). The tensile strength and Young's Modulus also calculated as shown in Table (6). From the figure and table it is cleared that the tensile strength of biocomposites from $0.008 \mathrm{wt} \%$ to $0.05 \mathrm{wt} \%$ increase with increasing MWCNTs concentrations; this may be attributed to the better reinforcement of the MWCNT when incorporated in the PVA/SA blend and hence better performance was observed [38], on the other hand, notes the results show a disturbances in Young's Modulus values and in tensile strength after 0.05 $\mathrm{wt} \%$, that due to the bad dispersion of MWCNTs, and this agreement with scanning electron microscope results. The results show that the incorporation of MWCNTs improving mechanical parameters including tensile strength, Young's Modulus of PVA/SA/MWCNTs biocomposites and it appears particularly in concentration $(0.05$ $w t \%)$ of MWCNTs which have the highest value of tensile strength and Young's Modulus. From the above, we conclude that the concentration of MWCNTs $(0.05 \mathrm{wt} \%)$ is the best in all results and measurements and maybe have a good potential use in medical applications.

J. Text.Color. Polym. Sci. ,15, No. 1 (2018) 


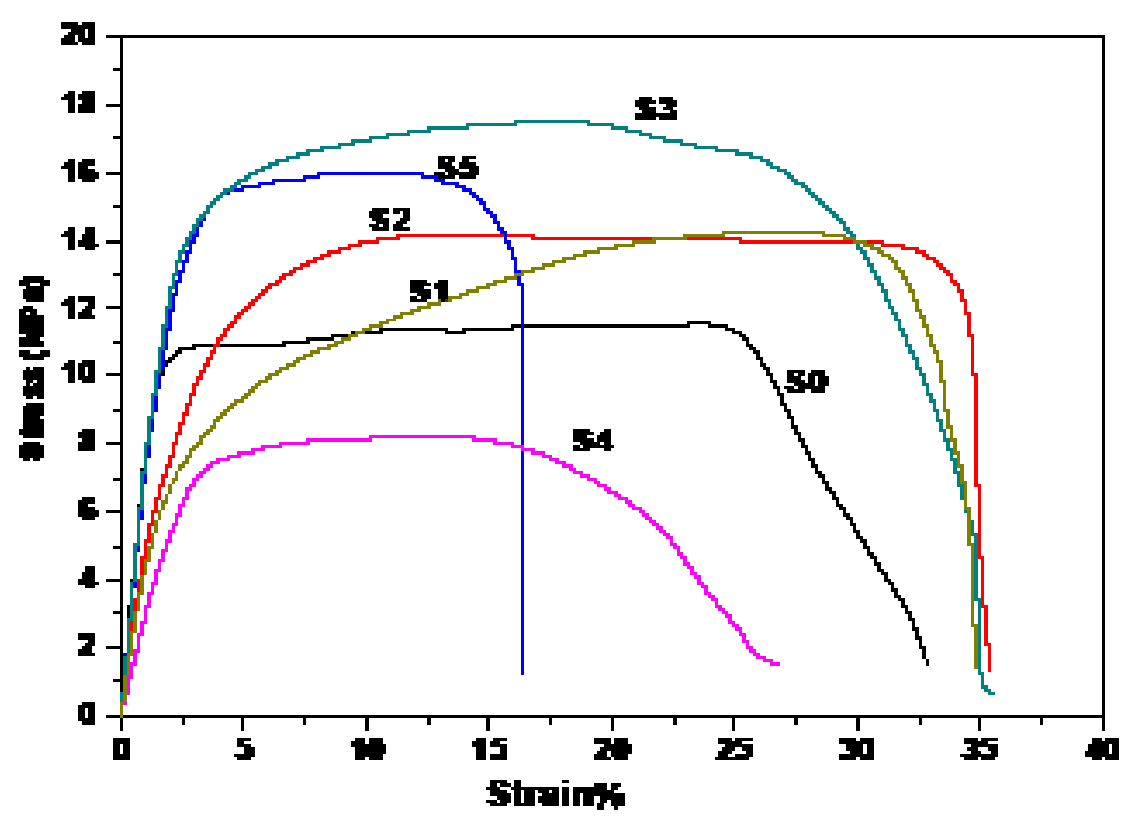

Fig. 10. mechanical analysis of PVA/SA blend with different concentration of MWCNTs.

TABLE 6. Tensile strength, Young's modulus of pure and prepared biocomposites.

\begin{tabular}{cccc}
\hline Sample & MWCNTs Wt\% & Tensil strength (MPa) & Young's Modulus (MPa) \\
\hline & & & \\
S0 & 0 & $11.4 \pm 1.32$ & $5.8 \pm 0.92$ \\
S1 & 0.008 & $13.9 \pm 1.95$ & $3.2 \pm 0.75$ \\
S2 & 0.02 & $15.9 \pm 2.1$ & $4 \pm 0.98$ \\
S3 & 0.05 & $17.4 \pm 2.27$ & $6.52 \pm 0.75$ \\
S4 & 0.08 & $8.2 \pm 1.12$ & $2.8 \pm 0.5$ \\
S5 & 0.1 & $14.18 \pm 1.68$ & $5.9 \pm 1.06$ \\
& & & \\
\hline
\end{tabular}

\section{Conclusions}

MWCNTs enhance the structural and mechanical properties of PVA/SA biopolymer blend. XRD and FTIR analysis confirmed the good miscibility of the two polymers and uniform distribution of CNTs inside the polymer matrix. The complexation between the PVA/SA and MWCNTs were shown using U.V. analysis. With increasing the MWCNTs concentrations the values of direct $\left(\mathrm{E}_{\mathrm{gd}}\right)$ and indirect $\left(\mathrm{E}_{\mathrm{gi}}\right)$ energy gap were decreased. The mechanical behavior was improved by increasing the MWCNTs percentage in biocomposites especially S3 sample. The physicochemical properties showed that MWCNTs with the ratio of $0.05 \mathrm{wt} \%$ have the J. Text.Color. Polym. Sci., 15, No. 1 (2018) optimum filler ratio. The obtained biocomposite is suitable for potential use in drug delivery and biomedical applications.

\section{Reference}

1. M. J. Folkes, P. S. Hope, Polymer blends and alloys (1993).

2. L. A. Utracki, B. Favis, Polymer alloys and blends, (Marcel Dekker: New York) (1989).

3. I. Elashmawi, N. Hakeem, E. Abdelrazek, Physica B: Condensed Matter, 403 (2008) 3547-3552.

4. M. Sivakumar, R. Subadevi, S. Rajendran, H.C. Wu, N. L. Wu, European Polymer Journal, 43 (2007) 4466-4473. 
5. A. M. Stephan, T. P. Kumar, N. Renganathan, S. Pitchumani, R. Thirunakaran, N. Muniyandi, Journal of Power Sources, 89 (2000) 80-87.

6. R. H. Y. Subban, A. K. Arof, European Polymer Journal, 40 (2004) 1841-1847.

7. M. M. Mahmud, A. Perveen, M. A. Matin, M. T. Arafat, Materials Research Express 5 (2018).

8. S. B. Bahrami, S. S. Kordestani, H. Mirzadeh, P. Mansoori, Iranian Polymer Journal, 12 (2003) 139-146.

9. J. E. Glass, Water-Soluble Polymers (Wiley Online Library) 1986.

10. P. B. Bhargav, V. M. Mohan, A. K. Sharma, V. V. R. N. Rao, Current Applied Physics, 9 (2009) 165171.

11. G. Zhao, J. Yang, Y. Wu, H. Zhao, Z. Wang, Materials Research Express, 5 (2018).

12. N. Bhattarai, M. Zhang, Nanotechnology, 18 (2007) Article 455601.

13. L. Sennerby, T. Röstiund, B. Albrektsson, T. Albrektsson, Biomaterials, 8 (1987) 49-52.

14. Z. Li, H. R. Ramay, K. D. Hauch, D. Xiao, M. Zhang, Biomaterials 26 (2005) 3919-3928.

15. U. K. Parida, A. K. Nayak, B. K. Binhani, P. Nayak, J. Biomaterials and Nanobiotechnology, 2 (2011) 414-425.

16. R. Sanderson, E. Immelman, D. Bezuidenhout, E. P. Jacobs, A. J. Van Reenen, Desalination, 90 (1993) 15-29.

17. R. Andrews, M. C. Weisenberger, Current Opinion in Solid State and Materials Science, 8 (2004) 31-37.

18. D. C. Davis, J. W. Wilkerson, J. Zhu, V. G. Hadjiev, Composites Science and Technology Journal, 71 (2011) 1089-1097.

19. I. Olivas-Armendáriz, P. García-Casillas, R. Martínez-Sánchez , A. Martínez-Villafañe, C. A. Martínez-Pérez, Journal of Alloys and Compounds, 495 (2010) 592-595.

20. P. Pötschke, T. D. Fornes, D. R. Paul, Polymer, 43 (2002) 3247-3255.

21. R. Haggenmueller, H. H. Gommans, A. G. Rinzler, J. E. Fischer, K. I. Winey, Chemical Physics Letters, 330 (2000) 219-225.

22. M. S. P. Shaffer, A. H. Windle, Advanced Materials, 11 (1999) 937-941.
23. J. Kim, H. Im, M. H. Cho, Wear, 271 (2011) $1029-$ 1038 .

24. A. N. Chakoli, J. Sui, M. Amirian, W. Cai, Journal of Polymer Research, 18 (2011) 1249-1259.

25. Z. Spitalsky, D. Tasis, K. Papagelis, C. Galiotis, Polym. Sci. 35 (2010) 357-401.

26. D. C. Wu, L. Shen, J. E. Low, S. Y. Wong, X. Li, W. C Tjiu, Y. Liu, Polymer, 51 (2010) 2155-2160.

27. Y. Li, H. Jia, F. Pan, Z. Jiang, Q. Cheng, J. membrane. sci. 407 (2012) 211-220.

28. R. Anbarasan , R. Pandiarajaguru, R. Prabhu, V. Dhanalakshmi, A. Jayalakshmi, B. Dhanalakshmi, J. Appl. Polym. Sci. 68 (2010) 117-2059.

29. R.Y. M. Huang, R. Pal, G. Moon, J. Membrane. Sci. 160 (1999) 101-113.

30. M. Theodore, M. Hosur, J. Thomas, S. Jeelani, Materials Science and Engineering A 528 (2011) 1192-1200.

31. N. Mott, E. Davis, Electronic processes in noncrystalline materials (Oxford University Press, New York) 1979.

32. D. S. Davis, T. S. Shalliday, Physics Review 118 (1960).

33. S. Jana, M. K. Trivedi, R. M. Tallapragada, A. Branton, D. Trivedi, G. Nayak, R. K. Mishra, J. Pharm. Anal. 6 (2015) 6-10.

34. T. M. M. Swamy, B. Ramarag, J. H. Lee, J. Appl. Polym. Sci. 109 (2008) 4075-4081.

35. M. Mohsin, A. Hossin, Y. Haik, J. Appl. Polym. Sci. 122 (2011) 3102-3109.

36. A. Szentes, C. S. Varga, G. Horváth, L. Bartha, Z. Kónya, H. Haspel, J. Szél, Á. Kukovecz, Express. Polym. Lett. 6 (2012) 494-502.

37. E. M. Abdelrazek, Physica B 400 (2007) 26-32.

38. C. P. Rejisha, S. Soundararajan, N. Sivapatham, K. Palanivelu, J. Polym. 2014 (2014) Article ID 157137.

(Received 20 / 11/2018; accepted $16 / 12 / 2018$ )

J. Text.Color. Polym. Sci. ,15, No. 1 (2018) 


\title{
توصيف ودراسات فيزيائية للبولي (كحول الفينيل)/الجينات الصوديوم/مخاليط حيوية من نانوتيوب كربونية متعددة الطبقات

\author{
'محروص شاكر ميخائيل , Y عبد الحميد محمد طاهر حزمهاd, ايسمه عادل محمد

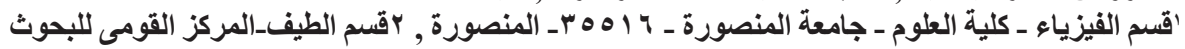

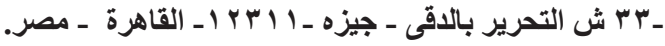

\begin{abstract}
اضافه انابيب الكربون النانونيه متعددة الطبقات الي مزيج من بوليمر البولى فينيل الكحول و الصوديوم الجينات,

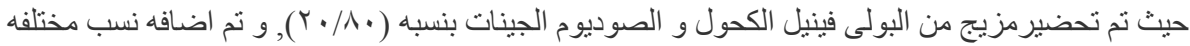

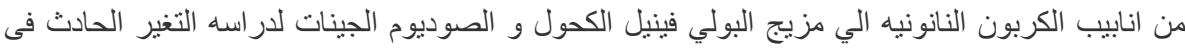

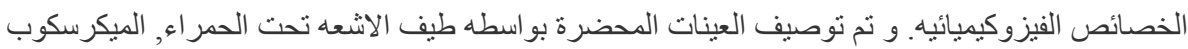

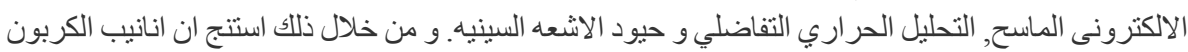

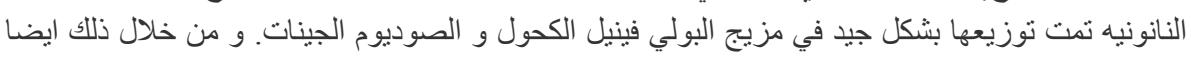

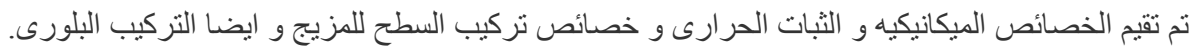

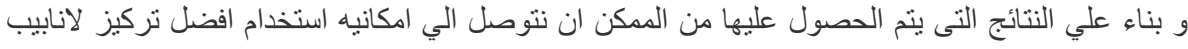

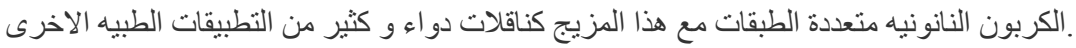

